\title{
SETI e a Grande História: Desafio e Extensão
}

Lowell S. Gustafson

Department of Political Science, Villanova University

Traduzido por Daniel de Pinho Barreiros

Correspondência | Lowell S. Gustafson, lowell.gustafson@villanova.edu

Citação | Gustafson, L. (2020) SETI e a Grande História: Desafio e Extensão. Traduzido por Daniel de Pinho Barreiros. Journal of Big History, IV(2); 32 - 45.

DOI | https://doi.org/10.22339/jbh.v4i2.4212

Resumo:* SETI é um dos relevantes desafios ao arcabouço da Grande História, e que expande seus propósitos. A Grande História tem exercido impacto similar sobre a história mundial, da mesma forma que as histórias nacionais impactaram as histórias religiosas. A Grande História busca empregar evidência e o melhor da análise teórica para integrar estudos sobre o cosmos, a Terra, a vida na Terra, e a humanidade. SETI compartilha desse interesse pelo cosmos, mas examina exoplanetas, astrobiologia, bem como possível inteligência extra-terrestre. Nesse artigo, consideramos as relações em desenvolvimento entre os propósitos da SETI e a Grande História.

Introdução

Histórias religiosas

Histórias políticas, nacionais e sociais

História mundial

\section{INTRODUÇÃO}

O passado simplesmente não é mais o que costumava ser. Ele continua mudando. $\mathrm{O}$ ponto em que começamos nossos relatos do passado tem variado ao longo do tempo. As histórias que examinamos se transformaram. Essas mudanças ocorrem por meio de um processo de desafio e extensão, e nos dizem muito sobre como entendemos a nós mesmos. Histórias políticas, nacionais e sociais desafiaram e mudaram as histórias religiosas e tradicionais. A história mundial desafiou e ampliou as histórias nacionais. A Grande História fez o mesmo com a história mundial. E a busca por inteligência extraterrestre (SETI) está entre os desafios que implicitamente exigem uma extensão analítica da própria Grande História.

Uma das características definidoras da humanidade é a memória, que difere da evidência do passado. Os condritos,
Grande História

Detecção e comunicação

Uma História de Maioridade

ou meteoritos que orbitam nosso Sol desde a formação do nosso Sistema Solar, nos fornecem evidências do que aconteceu no espaço há mais de 4,5 bilhões de anos atrás. Intrusões de rochas ígneas nos dão evidências do que aconteceu a milhões de anos atrás na Terra. Mas não costumamos considerar que essas evidências rememorem ou espelhem as condições das quais fizeram parte há muito tempo atrás.

Alguns afirmaram que as plantas são dotadas da capacidade de memorizar. ${ }^{1}$ Muitosanimais-chimpanzés, golfinhos, elefantes, pássaros, ratos e outros mostram sinais de serem capazes de lembrar-se do próprio passado, e dão indícios de como a memória os ajuda na preparação para o futuro. ${ }^{2}$

Humanos não apenas têm em comum a capacidade de lembrar, mas também podemos compartilhar e transmitir nossas memórias em um processo que David Christian chama de aprendizado coletivo. Podemos guardar

\author{
Cultura Popular \\ Uma História de Epílogos \\ Conclusões
}

ideias sobre o passado, mesmo quando aquilo de que lembramos não existe mais. Essa habilidade foi aprimorada com desenvolvimentos cognitivos que permitiram o pensamento simbólico. Os macacos vervet emitem sons distintos que alertam outros em sua tropa sobre a presença e o perigo representado por águias e leopardos. ${ }^{3} \mathrm{O}$ que eles não são capazes de fazer é usar esses sons na ausência do referente. Eles não ficam sentados à volta de uma fogueira à noite, com um pedido de desculpas: "Pensei que tinha visto uma águia hoje quando lhes chamei; mas era apenas um corvo. Desculpeme pelo alarme falso.” A evolução da capacidade de reter um pensamento e invocá-lo explicitamente por meio de sons atribuíveis e comunicáveis é um marco para os hominíneos.

A memória de todos os tipos de coisas que não existem mais pode parecer mais importante do que aquilo que existe no tempo presente. Lembrávamos-nos

\footnotetext{
* I am grateful for the generous support from the Subvention of Publication Program of Villanova University for preparation of this article. I am also grateful to Lacy Loar-Gruenler for her editing of this article; of course any mistakes or errors are my reponsibility.
} 
de nossos cuidadores dos tempos de criança muito tempo depois de terem morrido. A memória que tínhamos deles era real para nós, mesmo quando eles não existiam mais. Então, foi um pequeno passo para pensarmos que eles, assim como as memórias que temos deles, estavam vivos. Nossas memórias se tornaram seus espíritos. Nisso, a memória estava ligada a outra explosão cognitiva: a imaginação. Imaginamos o que nunca existiu e, em seguida, atuamos para dotar essas ideias de materialidade. Podemos assumir aqui que ninguém viu seus ancestrais na vida após a morte, mas temos atuado para prepará-los para isso por um tempo que antecede a própria história escrita. Pode ou não haver um Paraíso, mas há túmulos nos quais as pessoas parecem ter preparado seus ancestrais para o próximo mundo. Não apenas essas pessoas, mas os bens de que precisariam para viver bem na próxima vida, tinham espíritos. Então, enterramos panelas, armas, joias e outros itens com eles.

Outra maneira de imaginar veio da capacidade de reunir memórias das coisas que vimos, de modo a vislumbrar algo novo em nossos olhos "mentais". Um exemplo disso é a estatueta Löwenmensch ou Homem-Leão, uma escultura descoberta na Alemanha em 1939 (Figura 1). Podemos nos lembrar de ter visto um leão e um homem, mas nunca uma criatura que era ambos ao mesmo tempo. Nossa capacidade de imaginar uma síntese criou uma nova ideia, uma nova opção de algo que poderia ser. Ninguém jamais viu um homem-leão, mas um artista de 35.000 a 40.000 anos atrás podia imaginar e esculpir um a partir de uma peça de marfim. ${ }^{4}$ Naquela época, ninguém tinha visto uma cidade ou um computador, mas, eventualmente, pessoas imaginativas vieram a planejálos, e os criaram.

Memória e imaginação criaram o espaço para tudo que pode ser real para nós. Isso nos deu opções para concebermos àquilo de que fizemos parte ao longo do tempo; deu-nos opções também para concebermos os modos pelos quais participamos daquilo que veio antes - ou daquilo que virá depois de nós.

\section{Histórias religiosas}

Temos muitas maneiras de registrar nossas memórias. Métodos para registrar os dias e outras unidades, como meses ou anos, podem ter sido desenvolvidos desde o período neolítico. O arranjo lítico de Wurdi Youang, datado de 11.000 a 20.000 anos atrás, em Victoria, Austrália, parece ter servido a esse propósito. A famosa estrutura de Stonehenge na Inglaterra, construída entre 4.000 e 5.000 anos atrás, pode ter registrado e previsto os solstícios de inverno e verão. Várias construções maias, como o Caracol em Chichén Itzá, estão alinhadas com uma variedade de eventos celestes que marcam datas. Esses e muitos outros exemplos remetem a períodos anteriores à escrita, em que nossos

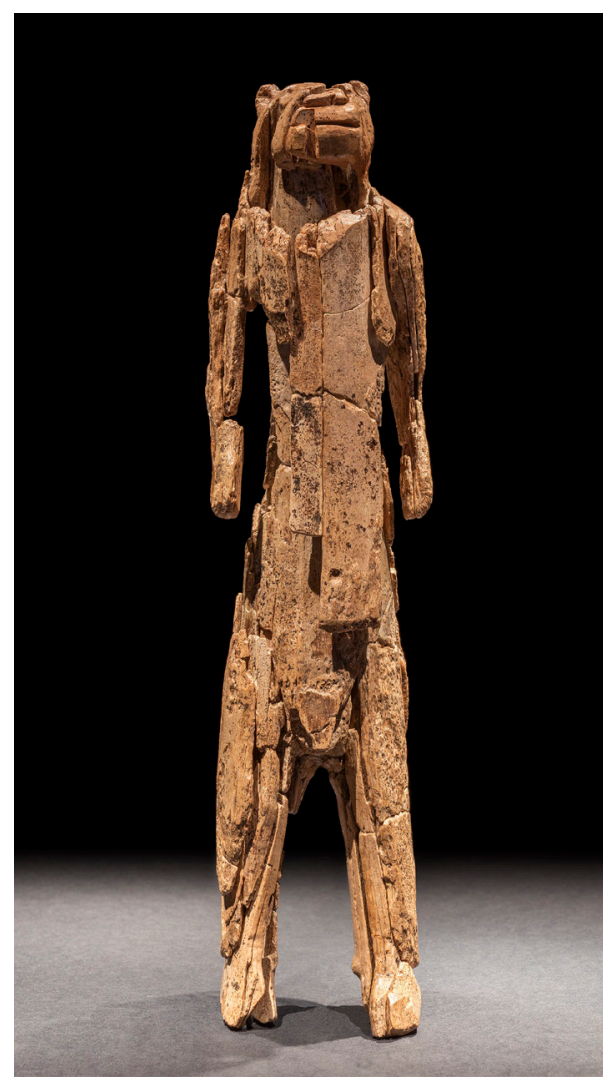

Figura 1: O homem-leão. ancestrais viam a si mesmos em relação com o cosmos, com seus eventos, e com fenômenos que se esperavam serem cíclicos. Memória e expectativa foram conectadas.

Pode-se pensar que esses eventos cósmicos estejam associados a outros tantos na Terra, como o aparecimento de certas plantas, movimentos de manadas ou a chegada de chuvas. As observações cosmológicas e sua associação com eventos locais se desenvolveram ou se tornaram parte do ritual e da religião. Elas também foram úteis no registro da passagem do tempo. As religiões geralmente registram o tempo de um evento importante em suas próprias histórias ou cosmogonias. Isso pode ter a ver principalmente com os ciclos anuais, que se repetem. O tempo cíclico tem sido frequentemente a norma. Às vezes, os ciclos anuais faziam parte de ciclos mais longos. Por exemplo, os maias tinham uma contagem de 365 dias em um ano (dezoito meses a cada vinte dias, com um mês de transição de cinco dias) ou Haab'. Um k'atun de vinte anos ou 7.200 dias, um baktun de 144.00o dias, uma "longa contagem" de treze baktuns, e um ciclo de 52 anos, ao Giro do Calendário, com base em uma comparação do calendário ritual de 260 com os Haab'. Eles tinham outras contagens de dias também. A antiga contagem maia antiga começou na data de criação mais recente, o equivalente a 11 de agosto de 3114 AEC no calendário gregoriano prolético.

Outros calendários religiosos também acompanham a passagem do tempo. Os calendários usados oficialmente na China antes de 1911 eram fundamentalmente calendários cíclicos (solar/lunar), que correspondiam a eventos astronômicos e sazonais, úteis aos agricultores. Contavam também com os "anos reais", Huang $\mathrm{Li}$, associados a uma sequência de imperadores. No calendário hindu, faz 5.122 anos desde que Sri Kṛșna retornou à sua morada eterna. Nos calendários budistas, Buda alcançou parinibbāna em 13 de maio de 544 AEC ou por volta disso. Yose ben Halafta, um rabino judeu do século II 
da Era Comum calculou que a criação começou em 679 Elul 25 do ano 1 (3761 $\mathrm{AEC})$. Maimônides, filósofo e cientista judeu do século XII, afirmou que o início da criação ocorreu no ano hebraico o (conhecido como "Anno Mundi o" em latim) e que a criação dos seres humanos ocorreu em Anno Mundi 1, que corresponde a 3761 AEC. O ano atual (2020 EC) no calendário judaico é o de 5780.5

Uma data tradicional é a data usada para a publicação desta edição: 2020. Essa data se referia ao número de anos desde o nascimento de Cristo. Santo Agostinho (354-430 EC), em seu trabalho, "O significado literal de Gênesis" (De Genesi ad litteram libri duodecim) argumentou que a Terra tinha cerca de 6.000 anos. James Ussher, líder religioso na Irlanda do século XVII, concordou aproximadamente com a data da criação ainda usada no calendário judaico, e por Agostinho. A leitura de Ussher dos textos bíblicos e de outros textos antigos o levou a estabelecer a data da criação "no começo da noite que precede o 23 de outubro... do ano 4004 anterior a Cristo". ${ }^{6} \mathrm{O}$ que importava para os cristãos não era tanto a criação do mundo, mas sua recriação em Cristo. Como foi escrito na epístola da Bíblia Cristã, 2 Coríntios 5:17,”... se alguém está em Cristo, a nova criação chegou: $\mathrm{O}$ velho se foi, o novo está aqui!?

A partir do segundo século depois de Cristo, alguns bispos do Império Romano do Oriente começaram a contar os anos desde o nascimento de Jesus. No entanto, vários estudiosos usaram calendários diferentes para colocar o nascimento de Jesus em anos ligeiramente diferentes. A questão ainda não havia sido resolvida nem três séculos depois. Dionísio, o Exíguo, também conhecido como Denis, o Pequeno, era um monge originário das atuais Romênia e Bulgária, que mais tarde atuou em Roma. Sua principal preocupação era a de localizar as datas da Páscoa em diferentes anos dentro do calendário litúrgico anual. Ele foi o primeiroa registrarque havia uma data para a Páscoa 525 anos após o nascimento de Cristo, ou no Anno Domini, AD, no ano de nosso Senhor. Alguns já haviam declarado que Cristo havia nascido 5.500 anos após a criação do mundo, e então previram que Jesus retornaria no ano de 60oo. "A Era da Encarnação... foi logo muito usada na Itália e, até certo ponto, um pouco mais tarde na Espanha; durante os séculos VIII e IX, foi adotada na Inglaterra. Dizem que Carlos Magno foi o primeiro governante cristão a empregá-la oficialmente. Somente no século $\mathrm{X}$ foi empregada na chancelaria papal. " " Esse sistema de datação atualmente se refere, em linhas gerais, ao

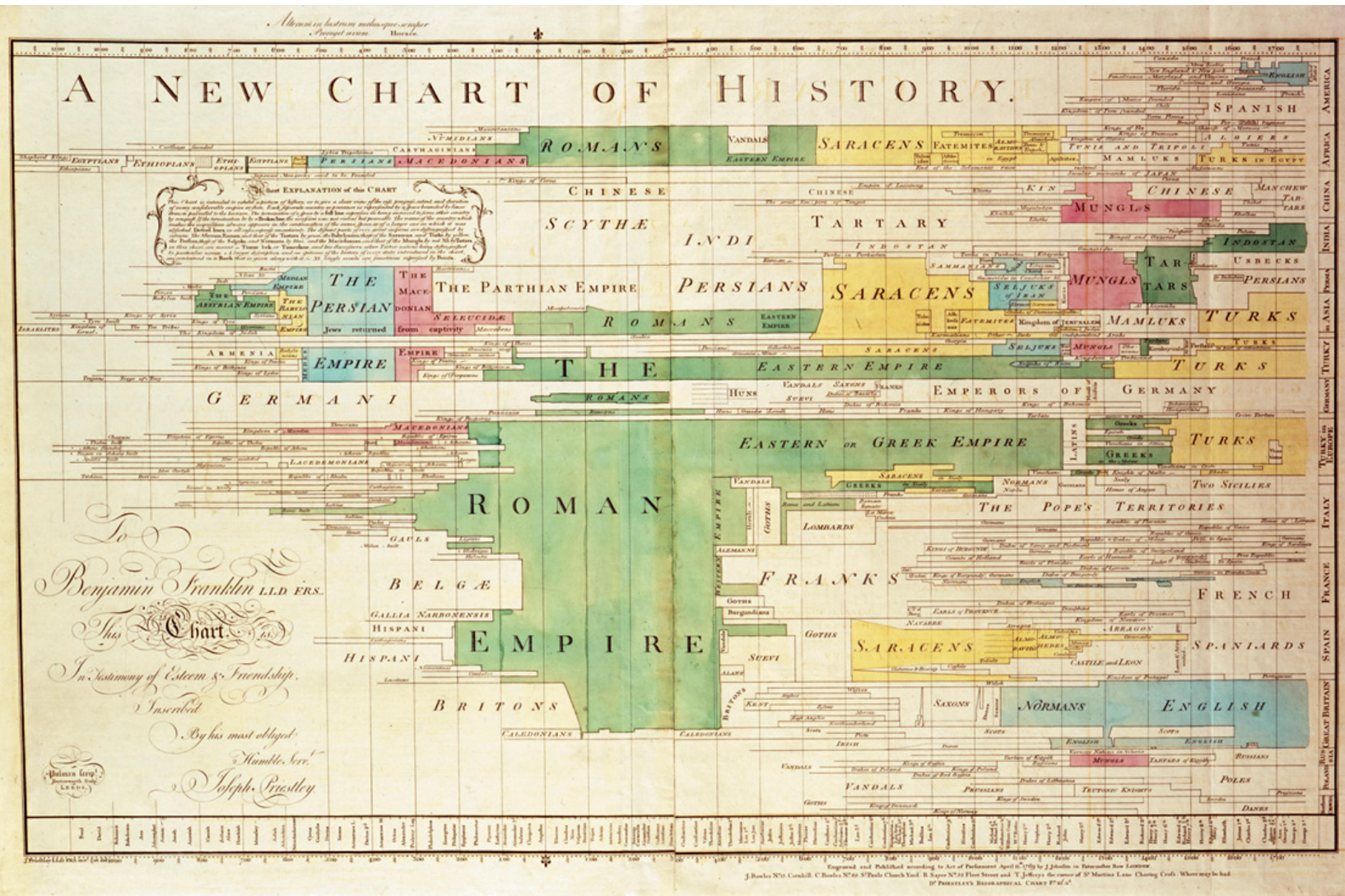

Figura 2. Una nuova carta storica. Inglese: una versione a colori di A New Chart of History di Joseph Priestly. "A Benjamin Franklin LLD. FRS. Questa carta a testimonianza di stima e amicizia. Firmato dal suo più grato e umile servitore. Joseph Priestley. 1769." 
início de uma Era Comum secular (EC), ou a um tempo Antes da Era Comum (AEC), substituindo a contagem "antes de Cristo" ou a partir do Ano de Nosso Senhor (AD ou d.C.). Mantém o número de anos por conveniência, mas rejeita a referência religiosa.

O Islã também começa sua contagem de anos a partir de um evento importante em sua história. $\mathrm{O}$ calendário islâmico calcula 1441 anos desde a migração de Maomé de Meca a Medina, conhecida como Hégira. Por muitos séculos, um grande número de pessoas se posicionou no tempo de acordo com essas estruturas religiosas que remontam a milênios.

\section{Histórias políticas, nacionais e sociais}

Nem sempre é fácil distinguir entre política e religião, uma vez que elas geralmente estão muito entrelaçadas. Os líderes políticos frequentemente reivindicam algum tipo de status religioso. Ainda assim, podemos ver como a contagem de anos nos calendários tem sido frequentemente definida politicamente. Pode começar com a chegada ao poder de um líder ou dinastia, ou em termos de histórias políticas nacionais.

Durante a República Romana, os anos também foram datados por consultas. Denis, o Pequeno, queria mudar o sistema comum de contar anos desde a fundação de Roma ou desde a chegada ao poder de Diocleciano, a Era dos Mártires.

Na história europeia, a soberania de Deus deu lugar à soberania dinástica após a Paz da Vestfália em 1648. Sob o princípio de Cuius regio, eius religio, (tal a religião do príncipe, tal um país), súditos leais aceitavam o catolicismo ou o ramo do protestantismo que seu monarca soberano professava. Ser um súdito leal do rei Henrique VIII significava ser um membro da Igreja Anglicana que ele dirigia. Especialmente com o Iluminismo e a Revolução Francesa, a soberania dinástica deu lugarà soberania nacional ou popular. Cidadãos da nação eram as pessoas que detinham soberania política. As histórias das nações, mais do que dinastias ou religiões, tornaramse o que importava. Como e quando uma nação se originou, e depois se desenvolveu?

Um exemplo disso é dado por Joseph Priestley, um teólogo separatista inglês do século XVIII, filósofo natural, químico e teórico político liberal. Ele foi creditado com a descoberta do oxigênio, entre outras realizações científicas. Em 1769, ele dedicou seu New Chart of History (veja a figura 2) a seu amigo e colega cientista, o politicamente engajado Benjamin Franklin. Ele não começou com a criação do mundo, um ponto de partida religioso ou com a chegada ao poder de um monarca. Em vez desses tipos de pontos de partida, ele começou sua história com as nações antigas de Israel e Egito. Certamente, esses eram pontos de partida nacionais que correspondiam ao sentido de tempo herdado da Bíblia. Mas sua enumeração não mencionou o Gênesis, o Rei Davi ou Zezer. Seu novo relato da história era global, bem como nacional; incluiu muitas, senão a maioria das grandes nações do mundo, e algumas regiões como Escandinávia, Polônia, Rússia, Grã-Bretanha, Espanha, França, Itália, Turquia na Europa, Turquia na

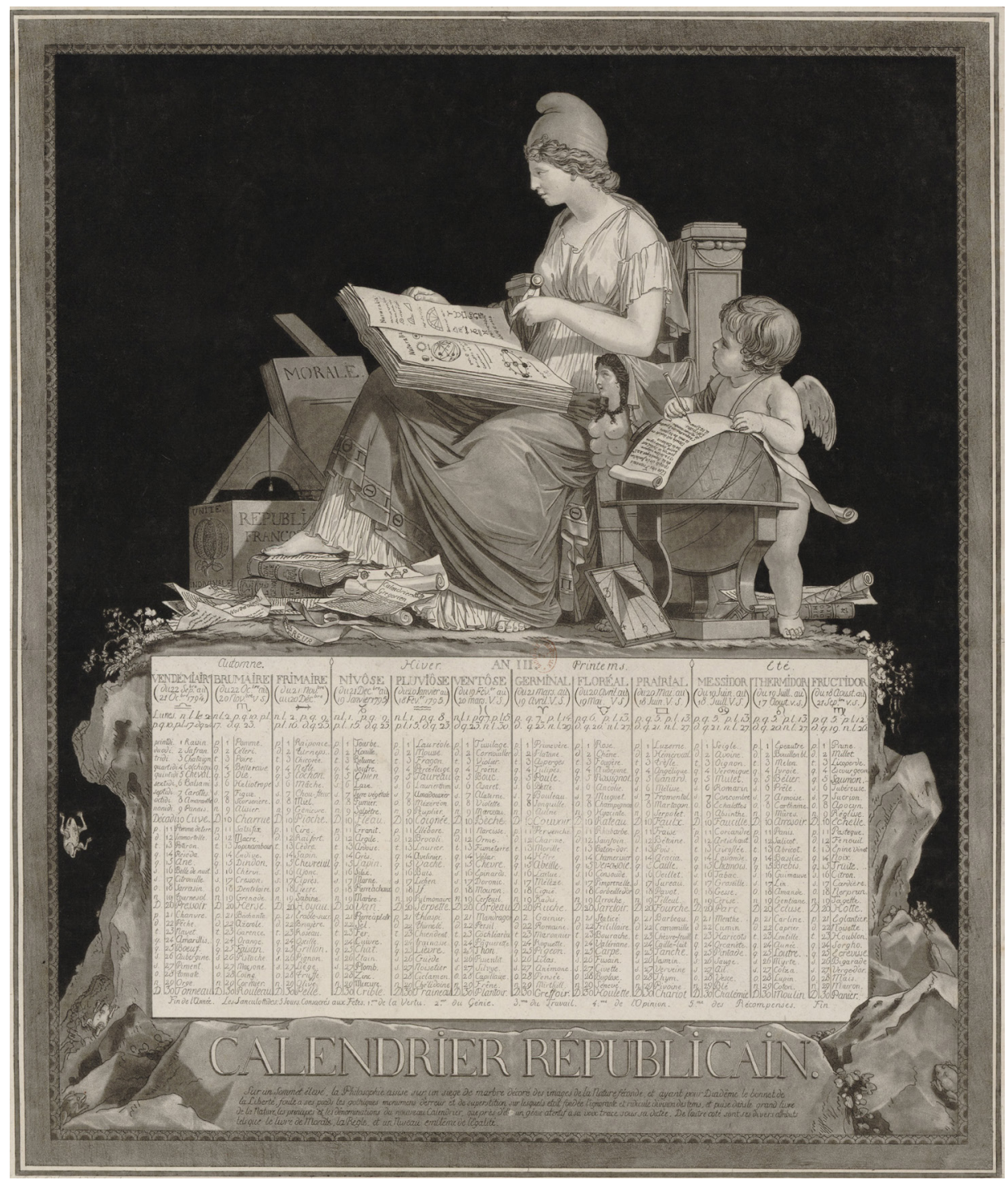

Figura 3. Calendario repubblicano ...: anno III: [stampa] / P.L. Debucourt del. et sculp. 1794, 
Ásia, Alemanha, Pérsia, Índia, China, África e América.

O calendário republicano (figura 3, abaixo) procurou situar o novo regime na França após a Revolução Francesa de 1789, em um período de tempo recém-planejado, racional e livre da superstição medieval. Não começou o registro do tempo com o nascimento de Jesus ou com Israel antigo. A contagem de anos começaria com os importantes acontecimentos recentes na França. As pessoas discordavam se a contagem de anos deveria começar com a Grande Revolução de 14 de julho de 1789 , mas aqueles que eram a favor do início da contagem de anos a partir da República em 22 de setembro de 1792 venceram a discussão. O tempo decimal foi considerado mais racional; portanto, cada dia deveria ter dez horas, cada uma com 100 minutos e cada minuto com cem segundos. Os limites exigidos pela racionalidade e o respeito à tradição clássica mantiveram o uso dos numerais romanos, como An (ano) I ou VI ou X. O calendário republicano foi usado na França por 12 anos, do final de 1793 a 1805 , e por 18 dias durante a Comuna de Paris em 1871.

O ensino da história nos Estados Unidos da América nunca resultou em um novo calendário, mas para muitos, a história nacional era a história que importava. Os documentos quase sagrados da nação, de 1776 e 1787, eram quasequedeimportância bíblica. Como escreve C. Bradley Thompson, Abraham
Lincoln parafraseou Provérbios (25:11) e "afirmou que o princípio da liberdade na Declaração de Independência era a palavra 'falada apropriadamente' que se mostrou um 'pomo de ouro' para nós ". A Constituição era a 'imagem de prata' que 'emoldurava' a Declaração. "1o A criação do mundo por Deus ou a nova criação em Cristo não pareceram mobilizar tanto quanto o Destino Manifesto da República em uma Terra Nova. A religião civil clássica da América é o ponto de partida para Walter A. McDougall iniciar seu Tragedy of U. S. Foreign Policy ". O papado teve sua sucessão remontando a Jesus; os Estados Unidos têm sua dinastia constitucional iniciada com George Washington. O ocupante mais

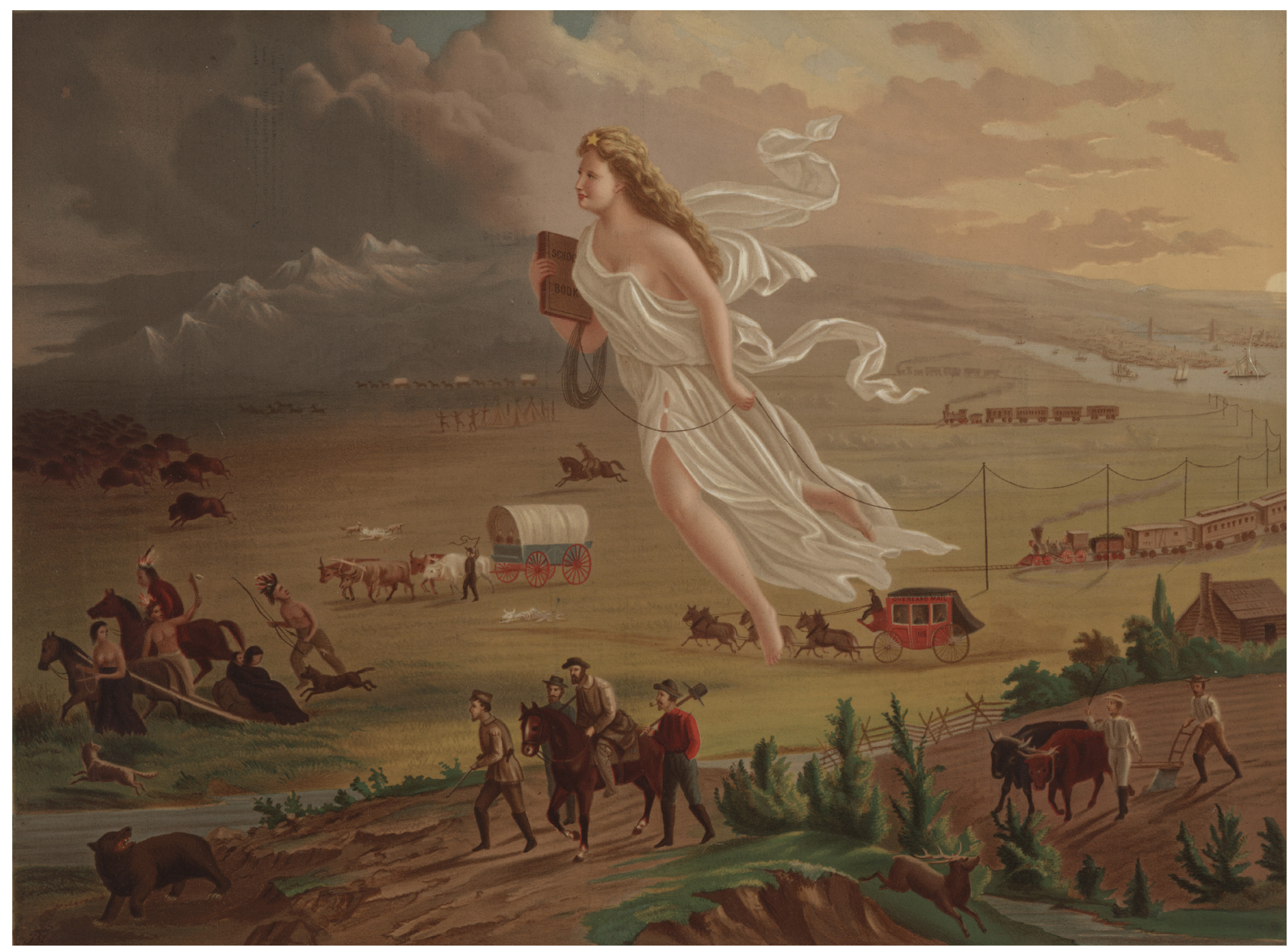

Figura 4. John Gast, American Progress, 1872. 
recente da sucessão presidencial é Donald Trump, o 45ํㅡㄹ detentor do cargo. Alguns americanos se orgulhavam da sucessão constitucional ininterrupta do poder, que remonta a 1789 .

A identidade política americana está ligada ao conhecimento da história da experiência nacional americana, que era um dos principais objetivos da educação pública. Quando a American Historical Association (AHA) foi fundada em 1884, ainda era recente a emergência da História como uma disciplina acadêmica distinta. "Os primeiros professores no campo da história foram nomeados nas principais universidades apenas na década de 1870". ${ }^{12}$ O país havia sobrevivido à Guerra Civil e o último prego de dormente da ferrovia transcontinental fora marretado em 1869. A nação havia alcançado seu Destino Manifesto de integrar território de mar a mar. Estava pronta para contar sua história. Em 1872, John Gast pintou seu "American Progress", mostrando uma mulher com cabelos loiros esvoaçantes e túnica branca ondulante voando como uma deusa sobre colonos e trabalhadores que estavam substituindo animais e povos selvagens $^{13}$ (Figura 4). O estado estava pronto para manter escolas públicas, em alguma medida para promover o nacionalismo e a boa cidadania. A história americana estava no currículo, não as histórias de todas as nações. Os americanos não foram os únicos que comemoraram sua história nacional. ${ }^{14}$ Existem muitas histórias de muitas nações cujo objetivo era o de incentivar a identidade política nacional. Figuras heroicas, grandes batalhas e eventos épicos formam as histórias de origem de muitas nações - e as identidades políticas de muitos cidadãos.

Da mesma forma, a American Political Science Association foi fundada algumas décadas após a AHA, em 1903. O estudo da ciência política, como o da história, foi associado à ideia de "ser americano" e até à de participar da vida pública americana. Cursos a respeito dos Três Poderes foram eventualmente complementados através de trabalhos sobre políticas étnicas, de classe e de gênero, junto com muitos outros subcampos. Conhecer e entender os eventos que levaram à Declaração de Independência, à Constituição, ao Discurso de Gettysburg, e a Carta de uma Prisão em Birmingham (bem como conhecer esses próprios textos em si) e muito mais se tornou parte de ser um bom cidadão americano.

Não apenas a história política americana apareceu como uma disciplina comum e parte importante da formação de identidades nacionais. Cursos sobre várias outras histórias nacionais, e às vezes regionais, têm sido frequentes: disciplinas sobre histórias britânica, francesa, russa, chinesa, africana, latino-americana têm sido comuns em universidades americanas e em outros lugares. Se os alunos saíam com alguma coisa, era a ideia de que as nações é que mereciam ser estudadas. O período histórico no qual cada curso costumava iniciar variava significativamente. As disciplinas começavam normalmente com estudo de alguns séculos no passado. Em alguns casos, como em cursos sobre a história romana ou chinesa antiga, podia começar com eventos de milênios atrás.

Durante a geração passada, o estudo e o ensino sobre as nações viveram tempos difíceis. Como observa Jill Lepore, os intelectuais "pararam de estudar a nação, acreditando que o estado-nação estava em declínio. O mundo se tornou global, unido por intrincadas redes de comércio e formas aceleradas de transporte e comunicação. Eles insistiram que o futuro era cosmopolita, não provincial. Por que se preocupar em estudar a nação? "15

Muitos historiadores começaram a se afastar das histórias políticas e nacionais em favor da investigação da história social, ou das histórias de raça, gênero, classe e outras categorias em vários períodos históricos envolvendo as últimas décadas, séculos ou milênios. Estudos de afro-americanos, afro-latino-americanos, mulheres, membros de comunidades LGBTQ e outros se tornaram muito mais comuns. A estes foram adicionadas histórias temáticas, como histórias ambientais. Estes cursos foram frequentemente ministrados como parte de um esforço para dar voz aos grupos até então sem voz ou pouco estudados. Ainda assim, a maioria das histórias nacionais, políticas e até sociais eram geralmente limitadas ao período do registro escrito do passado humano.

Todo mundo tem uma história, não apenas líderes políticos importantes e grandes nações. Se eles não se encaixavam perfeitamente em uma grande narrativa, tanto melhor. Grandes narrativas abrangentes acabaram excluindo grupos marginalizados e serviram aos interesses dos grupos que dominavam a criação da cultura.

\section{História Mundial}

Alguns historiadores buscavam uma estrutura maior do que o estudo de nações, tipos de regime ou grupos sociais. Pouco mais de um século após a formação da AHA, em 1982, alguns historiadores se uniram na World History Association para contar uma história da globalização. Essas eram histórias da humanidade, pelo menos desde o início das sociedades agrícolas. ${ }^{16}$ Os historiadores vasculham arquivos cheios de documentos primários, talvez voltando até à antiga Suméria. Até o momento em que a escrita se desenvolveu na Suméria, em 2700 AEC, havia diferentes grupos de pessoas vivendo em todos os continentes e regiões do mundo, exceto na Antártica. Os povos falavam línguas diferentes e haviam desenvolvido culturas distintas; as agora familiares diferenças físicas entre os povos eram visíveis. Diferenças civilizacionais, regionais, nacionais, étnicas e outras já estavam bem desenvolvidas. O início do estudo dos humanos nesse período de tempo deixa de fora um prelúdio muito longo.

Os historiadores cujo objetivo era o de promover uma identidade política global enfrentaram a tarefa de tentar construir pontes entre várias 
identidades culturais pré-existentes. Ao iniciar o ensino da história nos últimos milhares de anos, a narrativa começava com diferenças bem estabelecidas que muitas vezes levaram a conflitos. Essa abordagem começava com a diferença, e frequentemente com desconfiança e hostilidade. Que identidade política seria formada se os pontos de partida das histórias políticas retrocedessem para antes das origens das nações? Se a história política humana tiver começado na África há pelo menos 200.00o anos, então novas identidades humanas podem resultar a partir de cursos sobre política humana, além dos cursos sobre política americana, britânica, chinesa e outras.

Pode ser que, bem-vindas ou não, as histórias nacionais tenham retornado nos últimos anos. China, Índia, Estados Unidos, Grã-Bretanha e outros parecem estar interessados em tornar suas nações grandes novamente. Muitos viram um novo tribalismo na onda global de populismo dos últimos anos, em que vários grupos sociais buscam fronteiras mais impermeáveis. Mas outros desafiaram e procuraram expandir as histórias nacionais, sociais e até mundiais.

\section{Grande História}

William McNeill iniciou seu ttrabalho sobre a história mundial com a revolução na produção de alimentos entre 8500 e 7000 AEC. ${ }^{17}$ Ao fazer isso, ele usou outras fontes além das fontes escritas. Para discutirseu tópico, eleteve que se referir a artefatos e arqueologia. Isso abriu uma comporta para alguns historiadores que aprenderam com as ciências naturais a como ir além dos materiais escritos nos arquivos para examinar o passado pré-letrado. Esses historiadores começaram a colocar o registro escrito do passado humano no âmbito do registro natural de todo o passado conhecido. Ao fazer isso, eles entraram em um mundo intelectual que geólogos, astrônomos, astrofísicos, químicos, biólogos, antropólogos físicos e outros desenvolviam há séculos. Foram os cientistas naturais, e não os historiadores tradicionais e outros especialistas em humanidades e ciências sociais, que revolucionaram nossa compreensão de nosso lugar no passado. O passado não começou com a Epopeia de Gilgamesh, no Oriente Médio, cerca de 4.000 anos atrás, com os escritos da Bíblia ou com os Pré-Socráticos. Os cientistas aprenderam a ler as histórias contadas por luz, pedras, ossos e sangue. E essas histórias remetiam a cerca de milhões e bilhões de anos atrás. Os seres humanos foram realmente formados a partir dos mesmos elementos comuns na superfície da Terra, mas claramente não foram formados diretamente a partir de um punhado de argila. Os primeiros organismos unicelulares foram formados a partir dos elementos e compostos químicos encontrados na crosta terrestre. O próprio carbono, o hidrogênio, os aminoácidos e as proteínas tiveram longas histórias. Como Carl Sagan observou de maneira tão eloquente e famosa, somos todos feitos de matéria estelar. E então, como Walter Alvarez e outros argumentaram, a matéria estelar foi concentrada pela Terra. ${ }^{18}$ E depois foram necessários bilhões de anos de evolução entre os primeiros organismos celulares e humanos.

Eric Chaisson, David Christian, Fred Spier e muitos outros publicaram relatos baseados em evidências que vão do Big Bang há 13,82 bilhões de anos atrás, ao surgimento das estrelas e galáxias, elementos químicos, planetas sólidos como Terra, vida, evolução e cultura humana. A história não começou com nações, civilizações ou mesmo agricultura; iniciou com o começo do tempo e do espaço. ${ }^{19}$ Em 2010, a International Big History Association foi formada com o objetivo de examinar "a história integrada do Cosmos, Terra, Vida e Humanidade, usando as melhores evidências empíricas disponíveis e métodos acadêmicos". O boletim da IBHA, Origins, bem como o Journal of Big History apresentam escritos eartigos acadêmicos sobre esses tópicos. David Christian, que cunhou o termo Big History, publicou Origin Story: a Big History of Everything em 2018. ${ }^{20}$ O livro começa pelo Big Bang e chega ao Antropoceno, o período atual da história da Terra, quando os humanos têm o impacto dominante do planeta. ${ }^{21}$

Histórias de nações de todo o mundo desafiaram a ideia de que uma simples noção religiosa seja melhor para datar todos os eventos. A história do mundo desafiou a ideia predominante de dividir a humanidade em fronteiras nacionais e grupos sociais; buscou uma história integrada de toda a humanidade desde a revolução agrícola. A Grande História colocou essa história humana em seu próprio passado de cerca de 200.000 a 300.000 anos, e depois disso, nos muitos passos que tiveram que ser tomados ao longo de 13,82 bilhões de anos para chegar à Terra, à vida e à humanidade.

A nova visão de quem somos, de onde viemos, e do que somos parte, foi reforçada pela foto Earthrise, tirada em 24 de dezembro de 1968, pelo astronauta da Apollo 8, William Anders. É a foto que Fred Spier usou para a capa de seu livro Big History and the Future of Humanity. Ele refletiu sobre essa foto desde então. ${ }^{22}$ Ver a Terra do ponto de vista da Lua mudou quem somos. A linda Terra azul, branca e verde mostrada como uma joia em um espaço escuro e agourento. Não havia "Planeta B" para o qual pudéssemos escapar com nossa tecnologia, então ou agora, se acabarmos por tornar nossa Terra inabitável. Para muitos, velhas ideias de segurança nacional empalideceram em comparação com a segurança doméstica global.

\section{SETI e uma história de amadurecimento}

Por mais impressionante que a vista da Terra fosse da Lua, muitos se perguntaram se havia outros planetas habitáveis fora de nosso sistema solar. Já se imaginou um dia que Marte pudesse abrigar vida inteligente, mas agora sobre o planeta se impõem perguntas a respeito de abrigar ou não vida microbiana. Uma de nossas 


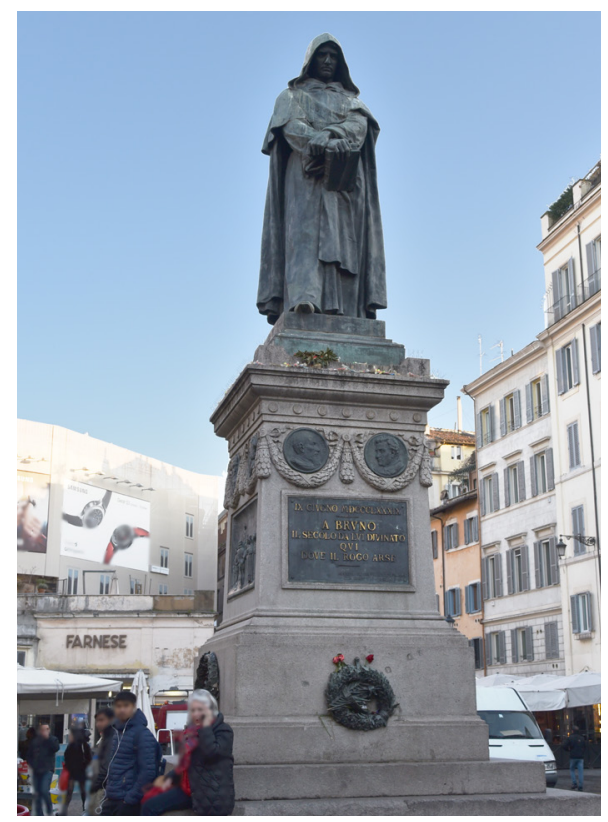

Figura 5: Local em Roma onde em 17 de fevereiro de 1600 Giordano Bruno foi morto na fogueira, em decorrência de suas visões heréticas. Foto de Lowell Gustafson.

melhores esperanças está nos mares de uma das luas de Júpiter, Io. A busca por exoplanetas (planetas fora do nosso sistema solar), pela vida em qualquer lugar do universo além da Terra, e pela inteligência extraterrestre, desafia e amplia a Grande História. Uma Grande História não é grande o suficiente para esses campos. Existem muitos planetas além da Terra; desde 2019, mais de 4.0oo foram detectados apenas dentro da área local de nossa própria galáxia. ${ }^{23}$ $\mathrm{O}$ número de planetas no universo com mais de 100 bilhões de galáxias deve ser fenomenal.

O interesse em haver possivelmente muitos outros planetas não tem sido exclusivo do nosso tempo. O cardeal alemão Nicolau de Cusa sugeriu no século XV que existiam outros planetas em torno de outras estrelas além do nosso sol. Ele escreveu que "a Terra é uma estrela como outras estrelas, não é o centro do universo, não está em repouso nem seus polos são fixos. Os corpos celestes não são estritamente esféricos, nem suas órbitas circulares".24 $O$ frade dominicano italiano do século XVI, Giordano Bruno, argumentou que as estrelas eram sóis distantes cercados por seus próprios planetas, além de afirmar que o universo é infinito e que não poderia ter um centro.

Em 1685, o autor francês Bernard le Bovier de Fontenelle publicou Conversations on the Plurality of Worlds. Ele escreveu não em latim, que era comum para os estudiosos da época, mas em francês, pois seu objetivo era tornar as ideias acessíveis à cultura popular. ${ }^{25}$

Uma grande diferença entre esses primeiros escritos e a SETI são os grandes avanços científicos e tecnológicos feitos nos últimos tempos, que nos permitem procurar evidências físicas de exoplanetas em vez de apenas especular sobre eles. Agora podemos usar a observação para estabelecer que existem outros planetas habitáveis, isto é, aqueles com água líquida, que podem hospedar a vida como a imaginamos.

Encontramos evidências de exoplanetas com sucesso; ainda estamos procurando evidências de qualquer outra vida, ainda que muito menos inteligente, além da Terra. A probabilidade de encontrarmos evidências ainda é uma questão em aberto. Em 1961, Frank Drake escreveu sua famosa equação que sugeria o que precisávamos saber antes de podermos calcular quantas formas de vida além da Terra existiam. Inicialmente,

Sendo

$$
N=R_{\star} \cdot f_{\mathrm{p}} \cdot n_{\mathrm{e}} \cdot f_{\mathrm{l}} \cdot f_{\mathrm{i}} \cdot f_{\mathrm{c}} \cdot L
$$

$N=\mathrm{o}$ número de civilizações em nossa galáxia com as quais a comunicação seja possível (ou seja, as que estão em nosso atual cone de luz do passado);

e

$R_{*}=$ a taxa média de formação de estrelas em nossa galáxia;

$f_{\mathrm{p}}=\mathrm{a}$ fração daquelas estrelas que possuem planetas;

$n_{\mathrm{e}}=\mathrm{o}$ número médio de planetas que podem potencialmente suportar a vida, por estrela que possui planetas;

$f_{1}=$ a fração de planetas que poderiam sustentar a vida, e que realmente desenvolve a vida em algum momento;

$f_{\mathrm{i}}=$ a fração de planetas com vida que acaba por desenvolver vida inteligente (civilizações);

$f_{c}=$ a fração de civilizações que desenvolvem uma tecnologia que libera sinais detectáveis de sua existência no espaço;

$L=$ o período de tempo durante o qual essas civilizações liberam sinais detectáveis no espaço

Somente na Terra, existe quase uma variedade infinita de formas de vida além dos seres humanos. Seria surpreendente se no número quase ilimitado de planetas dentro do universo existissem muitas outras formas de vida, incluindo as inteligentes? $\mathrm{O}$ interesse da Grande História pelo cosmos é bom; suas ênfases na Terra, na vida na Terra e na humanidade são míopes demais. Também precisamos pensar sobre e procurar exoplanetas, astrobiologia e exo-inteligência.

Para muitos, parecia provável que, com inúmeros planetas habitáveis, devia haver muitas formas de vida extraterrestres. ${ }^{26} \mathrm{O}$ grande físico ítaloamericano, Enrico Fermi também acreditava nisso, mas então se perguntou: "Então, onde estão?" ${ }^{27}$

\section{Detecção e comunicação}

Até agora, ainda não detectamos vida ou inteligência extraterrestre. Uma esperança ainda mais ambiciosa é a de que talvez possamos nos comunicar com vida extraterrestre ou formar algum tipo de relacionamento com os outros seres. ${ }^{28} \mathrm{E}$ mais ambiciosa ainda é a ideia de visitarem a Terra ou de nós viajarmos até eles. ${ }^{29}$ Dadas as enormes dificuldades de deslocamento por distancias tão vastas, certamente não teremos uma forma de fazê-lo agora ou no futuro próximo. Outras civilizações muito mais avançadas podem ter descoberto como viajar por tais distâncias, mas ainda não há evidências que persuadam os cientistas a respeito de tais visitas. Nem sequer detectamos a radiação de civilizações além da Terra, o que seria muito provável de ter acontecido. 


\section{Uma história de maturidade}

Embora não tenhamos encontrado exemplos da vida simples ou inteligente além da Terra, a pesquisa a esse respeito é importante. Por muitos séculos, pensamos que nossa Terra era o centro do universo. Pensávamos que éramos as únicas formas de vida no cosmos. Mesmo apenas um século atrás, bem depois de sabermos que orbitávamos em torno do sol, a maioria supunha que estávamos na única galáxia do universo. Somente após Edwin Hubble e outros provarem a existência de numerosas outras galáxias é que percebemos que não se tratavam de nuvens e nébulas que circulavam a Via Láctea. Antes de 1995, não tínhamos evidências de planetas fora do nosso sistema solar. Agora sabemos que existem milhares deles em alguns milhares de anosluz distantes de nós. Não assumimos que somos tudo o que existe. Nós procuramos e encontramos outros planetas. Nós procuramos vida além da Terra e vida inteligente além da Terra - e ainda estamos procurando.

Imaginar e procurar vida e inteligência extraterrestres representa o próximo nível de complexidade que a Grande História não havia enfatizado até aqui. A história da Grande História já versava sobre a crescente complexidade dos relacionamentos. A história dependia de relacionamentos anteriores, sendo incorporados, de forma emergente, em relacionamentos novos e mais complexos, com novas propriedades. A Grande História apresentou uma narrativa a respeito de quarks para cima e para baixo, que se relacionam no âmbito de nêutrons e prótons, mediados pela força nuclear forte. Prótons e nêutrons formaram relações com elétrons através da mediação da força eletromagnética. O equilíbrio dinâmico entre a gravidade e a fusão nuclear permitiu às estrelas formar núcleos com maior número de prótons do que os alcançados pelo hidrogênio e o hélio. Esses elementos, uma vez lançados no espaço por estrelas moribundas ou supernovas, conectaram-se no âmbito de compostos químicos multielementos. Com esse processo, além de estrelas de nêutrons colidindo umas com as outras, elementos mais pesados se tornaram disponíveis para formar planetas sólidos. Alguns como a Terra tinham vários níveis, com um núcleo metálico, magma, fundo do mar, placas continentais e muito mais. A química evoluiu para a bioquímica, que evoluiu para os conjuntos mais complexos de relacionamentos até então, no âmbito de vírus e células procarióticas unicelulares. Estes acabaram se tornando ainda mais complexos com a presença de novas organelas e de um núcleo nas células eucarióticas. Formas de vida multicelulares explodiram em um número quase infinito de formas no período cambriano. Um meteoro devastador pode ter causado a extinção de dinossauros não aviários, e ter dado aos mamíferos oportunidade para evoluir e eventualmente dar origem a Homo sapiens. Os relacionamentos entre indivíduos de nossa espécie incorporaram grupos de parentesco nômades, aldeias agrícolas assentadas, cidades, nações, impérios e frágeis instituições globais. Agora, com autores como H. G. Wells e os cientistas do SETI, poderíamos imaginar um nível seguinte, de relações interplanetárias e intergalácticas. A ideia era tão absurda quanto a de uma célula procariota em comparação com os primeiros átomos de carbono, hidrogênio e oxigênio.

Há um efeito irônico na maneira como entendemos a nós mesmos, a vida e a Terra, assim que começamos a pensar em outros planetas, formas de vida e seres inteligentes. Mesmo se não encontrarmos vida extraterrestre, a busca nos amadurece. Pensamos nas origensdeoutrosplanetas, outras formas de vida, outros seres inteligentes e não pensamos exclusivamente em nossas próprias origens. Esse processo não é uma história de origem para nós; é uma história de amadurecimento. Pode-se dizer que uma pessoa individual atinge a maioridade percebendo que outras pessoas existem independentemente, e têm suas próprias ideias, emoções e interesses. Alguns tiveram esse amadurecimento por um grande interesse na evolução de outras espécies aqui na Terra. A linha da vida corre não apenas para a humanidade, como na Declaração de Propósitos da IBHA, mas para um número quase infinito de outras espécies na Terra, e talvez além dela.

\section{Cultura Popular}

Muitas pessoas não esperaram meras evidências de vida e inteligência extraterrestres para imaginar o que elas poderiam ser e como isso nos afetaria. Formas de vida e civilizações altamente desenvolvidas em outros planetas chamaram nossa atenção em várias fontes fictícias, incluindo romances, filmes, histórias em quadrinhos, séries de televisão e músicas.

Percival Lowell popularizou a ideia sobre a vida inteligente em Marte em seus três livros: Mars (1895), Mars and its Canals (1906) e Mars as the Abode of Life (1908)..$^{\circ}$ Dois anos depois do livro de Lowell em 1895, H. G. Wells publicou seu romance $A$ Guerra dos Mundos. Em 1938, Orson Welles adaptou e narrou dramaticamente a história no rádio, causando pânico generalizado nos Estados Unidos. ${ }^{31}$

Avistamentos de UFOs eram mais comuns na década de 1950, mas ainda recebemos relatórios regularmente, com alguma suspeita de que nosso governo esteja suprimindo o conhecimento sobre eles por medo do pânico que causaria. ${ }^{32}$

Em 1966, os Byrds cantaram na música "Mr. Spaceman " sobre:

. . aqueles estranhos que vêm todas as noites

Aquelas luzes em forma de discos deixam as pessoas tensas

Deixam pegadas verde-azuladas que brilham no escuro

Espero que eles cheguem bem em casa.

A série de televisão Star Trek foi televisionada de 1966 a 69, e mantém desde então fãs dedicados. A série de filmes fenomenalmente bem- 
sucedida de George Lucas, Star Wars começou em 1977. Em 1982, vimos o magnífico filme de Steven Spielberg, ET, o Extraterrestre. Em 1997, Jodie Foster estrelou Contato, com base no livro homônimo de Carl Sagan. Não menos encantador foi Avatar de James Cameron, de 2009. A lista de relatos populares de vida extraterrestre é extensa. ${ }^{33}$ Aparentemente, não nos cansamos do medo, da maravilha, da excitação e da admiração provocados pela ideia do que pode significar, para nós, a vida em outros planetas.

Embora sejam frequentemente divertidos, também nos permitem refletir sobre o que a descoberta de vida extraterrestre significaria para nós. Vamos pedalar com E. T. no céu ou lutar contra Darth Vader em batalhas intergalácticas de alta tecnologia? As formas de vida extraterrestres que descobrimos serão apenas micróbios? Eles vão nos oferecer novos medicamentos ou doenças pandêmicas? Como imaginamos nosso relacionamento com eles? Existem sérias razões para sermos fascinados pela vida extraterrestre ainda não descoberta.

\section{Uma História de Epílogos}

A maioridade vem não apenas de um relacionamento, mesmo que apenas especulativo, com as formas de vida de outros planetas. Também vem de uma sensação de mortalidade. Mesmo se enfrentarmos o paradoxo de Fermi e encontrarmos evidências de outras formas de vida inteligente através da detecção de algum tipo de sinal de rádio, é provável que as novas formas de vida encontradas estejam a uma grande distância de nós. Em cinco mil anos-luz, procuramos apenas planetas habitáveis. Apenas nossa própriagaláxia tem 100.000 anos-luz de diâmetro. Mal começamos a explorar nossa própria galáxia; menos ainda os outros cem bilhões delas. Se recebermos um sinal a apenas mil anos-luz de distância, levará 2.000 anos, na melhor das hipóteses, até que façamos nossa resposta chegar a eles e, em seguida, que eles façam a sua nova resposta chegar a nós. Essa dificilmente é a taxa de comunicação sobre a qual se possa construir um relacionamento significativo. Qualquer de nós que receba um primeiro sinal vindo do espaço, e então mande uma resposta, estará decerto morto há muito tempo quando eles responderem de volta. O que é ainda mais incômodo, sua civilização ainda existirá quando finalmente formos capazes de fazer a mensagem chegar até lá? Talvez eles também estejam destruindo seu próprio meio ambiente, ou explodindo uns aos outros. Existiremos quando recebermos sua resposta? Depois de apenas alguns episódios em nosso diálogo com nossos novos amigos, é mais provável que tenhamos de admitir que nossa espécie terá sido extinta.

É certo que a Grande História tem se debruçado não apenas sobre origens; mas também sobre epílogos. Ouvimos os astrônomos e astrofísicos falarem sobre o nosso Sol se tornar uma gigante vermelha em cinco bilhões de anos, expandindo-se até evaporar os oceanos da Terra e fritar qualquer criatura que ainda tente sobreviver. $\mathrm{O}$ golpe de misericórdia virá da energia escura, que está afastando as galáxias de nosso universo umas das outras. Muitas continuam desaparecendo além do horizonte de eventos, para nunca mais serem vistas por nós. Com tempo suficiente, a maioria das galáxias em nosso universo terá desaparecido da nossa vista, deixando-nos com um céu predominantemente escuro. E então, nossas próprias galáxias locais e até a matéria poderão se desfazer. Chinua Achebe estava ainda mais certo do que imaginou; as coisas realmente desmoronam. ${ }^{34} \mathrm{Ou}$ as coisas são destruídas. Em longo prazo, tudo. Nesta visão, o Big Rip segue o Big Bang. Não apenas nós, como pessoas e como espécie, que terminamos; talvez o nosso sistema solar e todo o nosso universo. Nós sabíamos dessa possibilidade, mas tratar de "origens" soa como algo mais otimista. Talvez muitos de nós, já um tanto vetustos, sejamos como alguns adolescentes, que podem ser atrevidos porque pensam que são imortais. Se terminarmos nossa história com o Antropoceno, isso quase sugere que este é um período que durará para sempre. Mas não será. Homo sapiens existe por meros duzentos a trezentos mil anos. Quanto tempo sobreviveremos é uma incógnita, mas é altamente improvável que estejamos aqui até que a gigante vermelha em que nosso sol se transformará torne a vida na Terra impossível. Alguns têm demonstrado a ideia de que, esperançosamente, depois de concluirmos a destruição de nosso planeta natal, possamos migrar para outro. É material da ficção científica, por enquanto. Discutir como a humanidade, a vida, a Terra e os exoplanetas terminarão não é algo agradável, mas faz parte da nossa história de maioridade.

\section{Conclusões}

O SETI desafia e expande o propósito da Grande História de examinar o planeta Terra, a vida na Terra e a humanidade. Isso nos lembra de que uma miríade de outras formas de vida existe neste planeta, e que ainda mais podem existir em outros. Homo sapiens - "sábios" - pode ser apenas um dentre muitos tipos de seres inteligentes, cada um com suas longas e complexas histórias. De certa forma, recuperamos nossa posição no centro do universo, tal qual na cosmovisão ptolemaica. E justamente agora, que todos os outros planetas e galáxias em nosso universo também começaram no mesmo ponto, e que, do ponto de vista deles, tudo o mais está se expandindo a partir de sua localização. Todo lugar no universo é o centro do universo. Todo lugar - e toda forma de vida - tem sua própria história que remonta ao início dos tempos. $\mathrm{O}$ Big Bang leva progressivamente a nós e a tudo mais. O estudo da Terra, da vida e da humanidade precisa fazer parte do estudo de exoplanetas, da astrobiologia, de toda vida possível e de todas as formas de ser inteligente. $\mathrm{O}$ esforço pode nos ajudar a descobrir e amar o próximo. 


\section{Endnotes}

1 Sarah Abbott, "Plant Memory," Untamed Science, https:// untamedscience.com/biology/

plants/plant-memory/, ultimo acesso em 18 de dezembro de 2019; Gagliano M et al. 2014. Experience teaches plants to learn faster and forget slower in environments where it matters. Oecologia, publicado online em 05 de janeiro de 2014; doi: 10.1007/s00442-013-2873-7; Robert Krulwich, "Can a Plant Remember? This One Seems to - Here's the Evidence," National Geographic, 15 de dezembro de 2015, https://www. nationalgeographic.com/science/ phenomena/2015/12/15/can-aplant-remember-this-one-seemsto-heres-the-evidence/; Sarah Laskow, "The Hidden Memories of Plants, Atlas Obscura, 5 de setembro de 2017, https://www.atlasobscura. com/articles/plant-memoryhidden-vernalization, último acesso em 18 de dezembro de 2019.

2 Frans de Waal, "The Surprising Complexity of Animal Memories" The Atlantic, 2 de junho de 2019, https://www.theatlantic. com/science/archive/2019/o6/ surprising-complexity-animalmemories/58942o/, ultimo acesso em 17 de dezembro de 2019; PanozBrownetal., 2018, "Replay of Episodic Memories in the Rat," Current Biology 28, 1628-1634, https:// doi.org/10.1016/j.cub.2018.04.006, último acesso em 17 de dezembro de 2019; Christine Dell-Amore, Dolphins have the longest memories in the animal kingdom, August 6, 2013, National Geographic, https:// www.nationalgeographic.com/ news/2013/8/130806-dolphinsmemories-animals-sciencelongest/, último acesso em 17 de dezembro de 2019.

3 Klaus Zuberbühler, PredatorSpecific Alarm Calls in Campbell's Monkeys, Cercopithecus campbelli, Behavioral Ecology and
Sociobiology, Vol. 50, No. 5 (Oct., 2001), pp. 414-422, https://www. jstor.org/stable/4601985, último acesso em 16 de dezembro de 2019.

4 The Lion Man: an Ice Age masterpiece, The British Museum, https://blog.britishmuseum. org/the-lion-man-an-ice-agemasterpiece/, último acesso em 16 de dezembro de 2019.

5 David B. Green, This Day in Jewish History 3761 BCE: The World Is Created, According to the Hebrew Calendar and an Obscure Sage. Basing himself on no source but the bible, Rabbi Yose ben Halafta, who lived in the and century $C E$, sat down and did the math. Haaretz, 07 de outubro de 2015, último acesso em 10 de dezembro de 2019, https:// www.haaretz.com/jewish/3761-bcethe-world-is-created-1.5405777.

6 Ussher, James. Annales Veteris Testamenti, a prima mundi origine dedvcti: una cum rerum asiaticarum et ægyptiacarum chronico, a temporis historici principio usque ad Maccabaicorum initia producto. Londini, ex officina J. Flesher, \& prostant apud J. Crook \& J. Baker, 1650. Pdf. https://www.loc.gov/ item/21002221/. https://www.loc. gov/resource/rbctos.2017gen52659.

7 Taylor, J.H., translation and annotation of St Augustine, The Literal Meaning of Genesis (Augustine, De Genesi ad Litteram), Vol. 1, Newman/Paulist Press, New York, 1982. Veja também Augustine, The City of God, 12.10, 'Of the falseness of the history which allots many thousand years to the world's past', in Schaff, P. (Ed.), NPNF1-O2, ref 6, pp.232-233.

8 Declercq, Georges: Anno Domini. The Origins of the Christian Era. Turnhout Belgium. 2000.

9 Lersch, Chronologie, Freiburg, 1899, p. 233, cited in "Dionysius Exiguus," the Catholic Encyclopedia, http://www.newadvent.org/ cathen/o501ob.htm, último acesso em 13 de dezembro de 2019.

10 Thompson, C. Bradley. America's Revolutionary Mind (p. xi). New York, Encounter Books, 2019.

11 McDougall, Walter A.. The Tragedy of U.S. Foreign Policy: How America's Civil Religion Betrayed the National Interest. New Haven, Yale University Press, 2016, p. 25.

12 "Brief History of the A HA," American Historical Association, acesso em 17 de dezembro de 2019, http://www.historians.org/aboutaha-and-membership/aha-historyand-archives/brief-history-of-theaha.

13 John Gast, American progress, Library of Congress Prints and Photographs Division Washington, D.C. 20540 USA http://hdl.loc. gov/loc.pnp/pp.print, ppmsca 09855 http://hdl.loc.gov/loc.pnp/ ppmsca.09855, Reproduction Number: LC-DIG-ppmsca-09855 Library of Congress Prints and Photographs Division Washington, D.C. 20540 USA http://hdl.loc.gov/ loc.pnp/pp.print. Último acesso em 17 de dezembro de 2019.

14 Benedict Anderson, Imagined Communities: Reflections on the Origin and Spread of Nationalism (London: Verso,1991); Marc Ferro, The Use and Abuse of History: Or How the Past Is Taught to Children (London: Routledge, 2003); Ernest Gellner, Nations and Nationalism (Ithaca: Cornell University Press, 1983); Stephen J. Hartnett, Lisa B. Keranen, and Donovan Conley, eds., Imagining China: Rhetorics of Nationalism in an Age of Globalization (East Lansing, Michigan: Michigan State University Press, 2017); Derek Hastings, Nationalism in Modern Europe: Politics, Identity and Belonging since the French Revolution (London; New York: 
Bloomsbury Academic, 2017); Guntram Henrik Herb and David H. Kaplan, eds. Scaling Identities: Nationalism and Territoriality (Lanham, Maryland: Rowman \& Littlefield, 2018); John Hutchinson, Nationalism and War (New York: Oxford University Press, 2017); Fawcett Kohl, eds. Nationalism, Politics and the Practice of Archaeology (Cambridge University Press, 1996); Ronald Grigor Suny, "Constructing Primordialism: Old Histories for New Nations," The Journal of Modern History 73, no. 4 (Dezembro de 2001): 862-896.

15 Jill Lepore, This America: The Case for the Nation, New York, Liveright Publishing Corporation, 2019, p.15.

16 Um clássico do gênero é William $H$. McNeill, A World History, Oxford, Oxford University Press, 1979.

17 William H. McNeill, A World History, Oxford, Oxford University Press, 1967.

18 Olga García-Moreno, Luís Erick Aguirre-Palafox, Walter Álvarez, William Hawley. "A Little Big History of Iberian Gold," Journal of Big History, Volume 1, Issue 1, 2017, https://doi.org/10.22339/jbh. vii1.2243.

19 See, e.g. Craig Benjamin, Esther Quaedackers, David Baker, The Routledge Companion to Big History, Nw York, Routledge, 2020; Brown, Cynthia Stokes. Big History: From the Big Bang to the Present. New York: New Press: Distributed by W. W. Norton, 2007; Carroll, Sean. The Big Picture: On the Origins of Life, Meaning, and the Universe Itself. New York: Dutton, 2017; Chaisson, Eric. Epic of Evolution: Seven Ages of the Cosmos. New York: Columbia University Press, 2006; Christian, David. Maps of Time: An Introduction to Big History. The California World History Library. Berkeley: University of California Press, 2004; Christian,
David, Cynthia Stokes Brown, and Craig Benjamin. Big History: Between Nothing and Everything. New York: McGraw Hill Education, 2014; Dartnell, Lewis. Origins: How Earth's History Shaped Human History, New York, Basic Books, 2019; Hazen, Robert. Genesis: The Scientific Quest for Life's Origin. Washington, DC: Joseph Henry Press, 2005; Hazen, Robert. The Story of Earth: The First 4.5 Billion Years, from Stardust to Living Planet. New York: Viking, 2012; Rodrigue, Barry, Leonid Grinin, Andrey Korotayev, co-editors, From Big Bang to Galactic Civilizations: A Big History Anthology. Delhi: Primus Books, 2015-2016. threevolumes; Shubin, Neil. The Universe Within: Discovering the Common History of Rocks, Planets, and People. New York: Pantheon Books, 2013; Shubin, Neil. Your Inner Fish: A Journey into the 3.5-Billion-Year History of the Human Body. New York, Vintage, 2008; Spier, Fred. Big History and the Future of Humanity. Chichester, West Sussex, UK: John Wiley \& Sons Inc., 2015; Volk, Tyler, Quarks to Culture: How We Came to Be, New York, Columbia University Press, 2017.

20 David Christian, Origin Story: A Big History of Everything, New York, Little, Brown and Company, 2018. O livro foi publicado no Brasil pela Editora Companhia das Letras: David Christian, Origens: uma grande história de tudo. São Paulo, Companhia das Letras, 2019.

21 Archived copies of Origins may be found at https://bighistory.org/ members/origins-bulletin/; the Journal of Big History is at https:// jbh.journals.villanova.edu/.

22 Spier, F. (2019) On the social impact of the Apollo 8 Earthrise photo, or the lack of it? Journal of Big History, III(3); 117 - 150. https://doi. org/10.22339/jbh.v3i3.339o, último acesso em Dezembro 15, 2019.
23 Dennis Overbye, Search for Habitable Worlds Joined by New European Space Telescope, New York Times, Dezembro 18, 2019, https:// www.nytimes.com/2019/12/18/ science/cheops-satellite-launch. html ?action=click\&module= RelatedLinks\&pgtype=Article, último acesso em 23 de dezembro de 2019; Exoplanet Exploration: Planets beyond our solar system, NASA, https://exoplanets.nasa. gov/, último acesso em 16 de dezembro de 2019; Campante, Tiago L., Nuno C. Santos, and Mário J. P. F. G. Monteiro. Asteroseismology and Exoplanets: Listening to the Stars and Searching for New Worlds: IVth Azores International Advanced School in Space Sciences. Cham: Springer, 2018; Carroll, Michael. Earths of Distant Suns: How We Find Them, Communicate With Them, and Maybe Even Travel There. Cham: Springer International Publishing: Imprint: Copernicus, 2017; Exoplanet Discoveries: Have We Found Other Earths?: Joint Hearing Before the Subcommittee On Space \& Subcommittee On Research, Committee On Science, Space, and Technology, House of Representatives, One Hundred Thirteenth Congress, First Session, Thursday, May 9, 2013. Washington: U.S. Government Printing Office, 2013; Fontenelle, M. de 1657-1757., and John Glanvill. A Plurality of Worlds. London: Printed for R. Bentley and S. Magnes, 1688; Frank, Adam. Light of the Stars: Alien Worlds and the Fate of the Earth. New York, NY: W.W. Norton \& Company, 2018; Howard, Sethanne. "Exoplanets." Journal of the Washington Academy of Sciences 97, no. 3 (2011): 33-53; Kitchin, C. R. Exoplanets: Finding, Exploring, and Understanding Alien Worlds. New York, NY: Springer, 2012; Lemonick, Michael D. Mirror Earth: The Search for Our Planet's Twin. 1st U.S. ed. New York: Walker, 2012; Sage, Leslie. “Exoplanets." Nature 513, no. 7518 
(2014): 327; Seager, Sara. Exoplanets. Tucson: University of Arizona Press, 2011.

24 Nicholas of Cusa, Catholic Encyclopedia, https://www. catholic.org/encyclopedia/view. php?id=8455, último acesso em Dezembro 18, 2019; Nicholas of Cusa (1401-1464); also see The Internet Encyclopedia of Philosophy (IEP), https://www.iep.utm.edu/ nicholas/\#H4, último acesso em Dezembro 18, 2019.

25 Apluralityofworldswrittenin French by the author of the Dialogues of the dead; translated into English by Mr. Glanvill. Fontenelle, M. de (Bernard Le Bovier), 1657-1757., Glanvill, John, 1664?-1735. London: Printed for R. Bentley and S. Magnes, 1688. https://quod.lib.umich.edu/e/ eebo/A39871.00o1.oo1?view=toc, último acesso em, Dezembro 18, 2019.

26 Asimov, Isaac. Extraterrestrial Civilizations. New York: Crown Publishers, 1979; Dick, Steven J. Plurality of Worlds: The Origins of the Extraterrestrial Life Debate From Democritus to Kant. Cambridge [Cambridgeshire]; New York: Cambridge University Press, 1982; Dick, Steven J. Life On Other Worlds: The 2oth-century Extraterrestrial Life Debate. Cambridge ; New York: Cambridge University Press, 1998; Hamilton, Joseph. The Starry Hosts: A Plea for the Habitation of the Planets. London: Edinburgh: Simpkin, Marshall; A. Elliott, [etc.], 1875; Jayawardhana, Ray. Strange New Worlds: The Search for Alien Planets and Life Beyond Our Solar System. Princeton, N.J.: Princeton University Press, 2011; Linde, Peter. The Hunt for Alien Life: A Wider Perspective. 1st edition 2016. Cham: Springer International Publishing : Imprint: Springer, 2016; Macvey, John W. Whispers From Space. New York:
Macmillan, 1973; Morrison, Philip., John Billingham, and John Wolfe. The Search for Extraterrestrial Intelligence, SETI. [Washington, D.C.]: National Aeronautics and Space Administration, Scientific and Technical Information Office, 1977; Regis, Edward. Extraterrestrials: Science and Alien Intelligence. Cambridge [Cambridgeshire] ; New York: Cambridge University Press, 1985; Ross, Monte. The Search for Extraterrestrials: Intercepting Alien Signals. Berlin ; New York : Chichester, UK: Springer; published in association with Praxis, 2009; SETI: Search for Extra-terrestrial Intelligence. Washington, D.C.: Moffett Field, Calif.: Pasadena, Calif.: Washington, D.C.: National Aeronautics and Space Administration; Ames Research Center, SETI Office; Jet Propulsion Laboratory, California Institute of Technology, SETI Office ; NASA Headquarters, Office of Space Sciences and Applications, Life Sciences Division, 1990; Shuch, H. Paul. Searching for Extraterrestrial Intelligence: SETI Past, Present, and Future. Berlin; Heidelberg; New York: Chichester: Springer ; Praxis Publishing, 2011; Squeri, Lawrence. Waiting for Contact: The Search for Extraterrestrial Intelligence. Gainesville, Florida: University Press of Florida, 2016; Traphagan, John. Extraterrestrial Intelligence and Human Imagination: SETI At the Intersection of Science, Religion, and Culture. Cham: Springer, 2014; Vakoch, Douglas A., and Albert A. Harrison. Civilizations Beyond Earth: Extraterrestrial Life and Society. New York: Berghahn Books, 2011; Waldrop, M. Mitchell. "The Search for Alien Intelligence: SETI Is Dead ? Long Live SETI." Nature 475, no. 7357 (2011): 442-444; Wall, Michael. Out There: A Scientific Guide to Alien Life, Antimatter, and Human Space Travel (For the Cosmically Curious). Grand Central
Publishing, New York, 2018.

27 Milan M. Cirkovic: The Great Silence: The Science and Philosophy of Fermi's Paradox: Oxford University Press, Great Clarendon Street, Oxford OX2 6DP, United Kingdom, 2018; Davies, P. C. W. The Eerie Silence: Renewing Our Search for Alien Intelligence. 1st U.S. ed. Boston: Houghton Mifflin Harcourt, 2010; Webb, Stephen. If the Universe Is Teeming With Aliens ... Where Is Everybody?: Seventyfive Solutions to the Fermi Paradox and the Problem of Extraterrestrial Life. 2nd Ed. Springer, 2015.

28 Hippke, Michael. "Interstellar Communication: The Colors of Optical SETI." Journal of Astrophysics and Astronomy 39, no. 6 (2018): 1-16; Vakoch, Douglas A. Communication With Extraterrestrial Intelligence. Albany: State University of New York Press, 2011.

29 Haswell, Carole A. Transiting Exoplanets. Cambridge: Cambridge University Press, 2010.

30 Percival Lowell, Mars, Boston, Houghton, Mifflin, 1896, https://archive.org/details/ marsbypercivallooolowe/page/ n8; Mars and its canals, New York, The Macmillan company; London, Macmillan \& co., ltd., 1906, https://archive.org/details/ marsanditscanaloılowegoog/page/ nı3; Mars as the Abode of Life, New York, The Macmillan company, 1908, https://archive.org/details/ agg9438.ooo1.oo1.umich.edu/ page/n2, último acesso em 20 de Dezembro de 2019.

31 H. G. Wells, The War of the Worlds, Last Updated: September 20, 2019, Project Gutenberg, https:// www.gutenberg.org/files/36/36h/36-h.htm, o original de 1938 está disponível em vários links como https://www.youtube.com/ 
watch?v=997 $\mathrm{tN}_{7} \mathrm{MhQ}_{4} \mathrm{I}, \quad$ último acesso em 16 de dezembro de 2019.

32 E.g., Donald Keyhoe, Flying Saucers from Outer Space, New York, Henry Holt 1953.

33 See,e.g.Extraterrestriallifeinpopular culture, https://en.wikipedia.org/ wiki/Category:Extraterrestrial_life_ in_popular_culture; List of films featuring extraterrestrials, https:// en.wikipedia.org/wiki/List_of_ films_featuring_extraterrestrials; Songs about extraterrestrial life, https://en.wikipedia. org/wiki/Category:Songs_ about_extraterrestrial_life; Books about extraterrestrial life, https://en.wikipedia.org/ wiki/Category:Books_about_ extraterrestrial_life, último acesso em Dezembro 20, 2019.

34 Achebe, Chinua. The African Trilogy. (London: Everyman's Library, 2010)
ISBN 9781841593272. Edited with an introduction by Chimamanda Ngozi Adichie. Things Fall Apart, No Longer at Ease, and Arrow of God in one volume. 